\title{
Resenha da obra Fraternidade: para resistir a crueldade do mundo, de Edgar Morin.
}

\section{Dinora Tereza Zucchetti}

Por que resenhar um livro sobre o tema da fraternidade em tempos de tantas crueldades, como sugere o próprio título da obra? Por que resenhar um livro que tem pouco mais que meia centena de páginas? Essas, entre outras, foram as questões que me aturdiram após a leitura desta obra de Edgar Morin (2019). Talvez, entre as respostas, a mais eloquente possa estar no desejo de compartilhar a urgência do tema.

Estudiosa do autor, com quem dialoguei, em especial, durante o doutorado, no Programa de Pós-graduação em Educação, na Universidade Federal do Estado do Rio Grande do Sul, ainda mantenho uma relação intensa com seus escritos. Agora, como docente do Programa de Pós-graduação em Diversidade Cultural e Inclusão Social, coordeno uma disciplina de Leituras Orientadas, na qual estudamos algumas de suas obras. Para os discentes, trata-se de uma oportunidade de conhecer parte da imensa bibliografia produzida pelo sociólogo francês, atualmente com 99 anos de idade e, a meu ver, um dos estudiosos mais emblemáticos na compreensão da humanidade e seus acontecimentos, atento aos mitos e ao imaginário no contemporâneo.

E é sobre humanidade que trata "Fraternidade: para resistir a crueldade do mundo", um pequeno, mas gigante livro, que, no meu entender, é, também, uma obra autobiográfica, em que, buscando colocar foco naquilo que tanto nos falta, como afirma Morin (2019), aborda uma humanidade que é a expressão da unidade humana e o tesouro da diversidade. Na obra, o autor resgata memórias de verdadeiros amigos-amores, de filmes e de livros que foram fundamentais e inesquecíveis às suas experiências de fraternidade. Em pelo menos duas seções, rememora a vida, relembrando os tempos da resistência, enquanto ressalta que a aventura da escrita de "O Método" só foi possível nos oásis fraternais da Bolgheri, na Toscana, quando viveu na casa de amigos.

A mim, o livro "Fraternidade" recuperou a possibilidade de, a partir de mais uma obra de Morin, dialogar com autores-referência nas ciências humanas e sociais e, desse modo, revisitar ideias sobre o paradigma da ciência, na perspectiva da complexidade - enquanto aquilo que é tecido junto, presentes em outros estudiosos, como Humberto Maturana, Zygmunt Bauman, Leonardo Boff.

Morin, em "Fraternidade" (2019), apresenta o livro dividido em 12 seções temáticas, seguidas por notas e bibliografia. Suas reflexões iniciam na seção de número 1, sob o título "Liberdade, Igualdade e Fraternidade", em que apresenta características para cada um dos termos. Também relaciona a liberdade à economia, no sentido do liberalismo econômico e seus reflexos sobre a desigualdade, assim como, da igualdade, recupera o impacto sofrido pela liberdade. Perguntase, também, sobre a possibilidade de assegurar a combinação de ambas e, para tanto, recobra a força da legislação, a exemplo da seguridade social. Enfatiza, com base nessa premissa, que a

* Doutora em Educação pela UFRGS (2002), graduada em Serviço Social pela Universidade de Caxias do Sul. Professora titular da Universidade Feevale no Programa de Pós-Graduação em Diversidade Cultural e Inclusão Social. É bolsista Produtividade em Pesquisa (CNPq).E-mail: dinora@feevale@br.

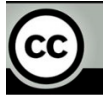


fraternidade não pode ser imposta por meio de leis, porque ela "só pode originar-se das pessoas humanas. A fraternidade existe em nós. Onde?" indaga o autor (2019, p. 12). Na base da discussão, a afirmação de que todo o sujeito possui dois softwares: um, de base egocêntrica, 'sujeito reflexivo-eu', é necessário à autopreservação; o outro, tendo o sentimento como substrato a nos impulsionar em relação ao outro, tem por base o 'eu'/ 'nós'.

Na seção seguinte, discute a existência de dois tipos de fraternidade, uma aberta e outra fechada. A fechada existe, afirma Morin (2019), quando o 'nós' limita tudo e todos ao que nos é estranho. Para exemplificar, utiliza o exemplo da Pátria como uma fraternidade ambivalente, pois, ao mesmo tempo em que devemos a ela obediência e amor, quando uma nação se fecha na tese do nacionalismo, fica excluída toda a possibilidade de patriotismo, impossibilitando uma fraternidade aberta ao estrangeiro, ao refugiado, ao migrante. Nesse sentido, não é possível deixar de lembrar o quanto o cinema tem explorado a relação entre o nacionalismo e a barbárie. Recentemente, o filme Zoológico de Varsóvia (2017), de Niki Karo, abordou o tema de modo a apresentar a solidariedade e a fraternidade como formas radicais de enfrentamentos à discriminação e, no seu extremo, ao extermínio. Filme e livro foram um feliz encontro para pensar sobre como temos nos constituído enquanto humanidade.

Em "Fontes biológicas da fraternidade: a ajuda mútua", outra seção do livro, o autor afirma que, tal como a vida uni e pluricelular, as relações sociais são constituídas por simbioses. Aborda, para tanto, o mutualismo e o comensalismo, forças de associação e destruição, no intuito de apontar não somente o antagonismo, mas também a complementariedade, essenciais à solidariedade, como características construtivas da vida. Para Morin é, pois, "[...] preciso integrar a visão de ajuda mútua de Kropktin com a visão darwiniana da seleção e associar essas duas noções antinômicas, no entanto, indissoluvelmente ligadas: a cooperação e o conflito" (p. 20), as quais são dialógicas.

Em tempos de Covid-19 no mundo, essa discussão não poderia estar mais atualizada. A pandemia escancarou conflitos político-ideológicos entre estados-nações, aproximou países cujos interesses políticos estão alinhados por meio de comunidades de interesses, distanciou aqueles cujos vínculos são mais oficiais e menos colaborativos, a exemplo do Mercosul. No campo de micropoderes, cooperação e conflito vêm sendo observados no cotidiano das cidades, nas relações de vizinhança, nas instituições sociais em que, nem sempre, o diálogo, a exemplo do que sugere Morin, tem sido um marco na construção de ideais que visem à solidariedade orgânica.

"Concordia e discórdia são o pai e mãe de tudo" (MORIN, 2019, p. 22), escreve o estudioso, aludindo a Heráclito de Éfeso, filósofo considerado o pai da dialética, a quem Morin, no conjunto da sua obra, recorre com frequência, em busca de elementos para empreender uma cosmovisão que considera a auto-eco-organização dos seres vivos. Contudo, mediante forças de união, são confrontadas forças de destruição e de morte - enquanto a concórdia cria organizações por associações sistêmicas, a discórdia desintegra os sistemas.

Da mitologia, Eros, Pólemo e Tânatos são trazidos ao texto para elucidar o fenômeno. Morin conclui a seção, identificando as ajudas mútuas e as associações como indispensáveis para fazer culminar o amor e a fraternidade presentes na infância e seus jogos na confraternização juvenil, além da possibilidade, ou não, da conservação de ambas na vida adulta. Acresce, na seção seguinte, a concepção de sororidade, sinônimo de irmandade, como cerne de toda a vida. A vida, contudo, não é somente feita de fraternidades duradouras, afirma Morin (2019). Existem momentos provisórios de fraternidades. A alegria nas festas de amigos, os encontros durante viagens, uma vitória no futebol são "momentos em que dois seres humanos se consideram mais 
que camaradas - são momentos solares que reaquecem o caminho de nossas vidas em um mundo prosaico" (MORIN, 2019, p. 34).

Em “Individualismo e Solidariedade”, aponta para o primeiro, também, como portador de positividades, enfatiza a autonomia pessoal necessária à criatividade, à responsabilidade e à emancipação individual e social. Apesar disso, ressalta que o individualismo, quando exacerbado, possui aspectos ambivalentes, como a competição e a concorrência, que, muitas vezes, convertem-se em obsessões, como o embrutecimento pela ganância de sempre lucrar. Dentre os aspectos negativos, cita o egoísmo, o enfraquecimento de laços de vizinhança nas grandes e pequenas cidades e nas zonas rurais, o trabalho hiperespecializado e, sobremaneira, o uso do cálculo para narrar experiências humanas, ao que nomeia de "perda de sentido da solidariedade" (MORIN, 2019, p. 37). Mesmo assim, das 'fraternidades adormecidas' e do individualismo geralmente renascem, de maneira espontânea, em casos de catástrofes, uma solidariedade que põe as pessoas em movimento. Isso, de fato, acontece; temos exemplos quase que diários desse renascimento, contudo, a solidariedade tende a desaparecer do mesmo modo que surge. Por que tão volátil?

Em "Paradoxo da mundialização", o autor observa que a globalização do mundo criou uma comunidade de destino e com ela um grande paradoxo, o qual se expressa, por um lado, no que denomina de identidade antropológica - que está a serviço de nos unir - e, de outro, pela existência de perigos globais comuns. Não há dúvida: dos perigos globais, o mais recente é a pandemia do novo Corona vírus e o reflexo dela sobre a 'normalidade' da vida.

Desse modo, da diversidade manifestada nos fenótipos, nas línguas, nas culturas, entre outros, a qual deveria nos remeter a uma fraternidade planetária, baseada na aventura comum, somos jogados mediante culturas particulares, fechamento de fronteiras de regiões, países, com o objetivo de impedir a livre circulação, no caso, numa tentativa de diminuir o avanço da Covid-19. Nada mais literal que isso! Por outro lado, não é possível deixar de lembrar que fronteiras e embates travados nas dimensões da vida humana - diversidade/particularidade - não são exclusivas do contexto pandêmico, ainda que este tenha proporções mundiais e, de certo modo, tenha tirado de centralidade outras tantas formas perversas de interdições sobre o humano.

Em “Oásis de fraternidade”, Morin faz referência à capacidade do humano de multiplicar experiências "para escapar dos tentáculos dos poderes tecnoeconômicos” (MORIN, 2019, p. 43). Aborda, portanto, a utilização de energias limpas, os alimentos orgânicos de produção local, a renúncia ao descartável e ao que tem obsolescência programada. Também chama atenção para as redes mundiais de trocas e de ajuda mútua, a economia solidária, o compartilhamento de saberes e de ferramentas tecnológicas. Para exemplificar, apresenta, a partir da experiência da moeda local e do serviço de microcrédito do Banco Palmas, situado no bairro Conjunto Palmeiras, na cidade de Fortaleza, o impacto social sobre uma comunidade dentre as mais vulneráveis daquela capital nordestina, ressaltando a positividade como capacidade de resistência humana, concepção tão fundamental para Morin.

Na seção "Mudar de via?", questiona acerca da possibilidade de um transumanismo capaz de prolongar a vida com saúde e aumentar as competências das pessoas, proveniente do resultado da simbiose homem-máquina. Não o faz, contudo, sem se esquecer de nominar o cenário de desastres ecológicos, políticos, sociais e de desumanização crescente. Para mudar a via, o autor afirma a necessidade de transformar a maneira de pensar. Sugere, nesse sentido, a busca pela religação, pela complexidade, também presentes nas solidariedades tradicionais, no retorno ao oásis da vida. "Qual será o futuro? Ele é incerto. Os mesmos motores acoplados que doravante impulsionam a nave espacial Terra - ciência, técnica, economia - caminham rumo ao sentido 
catastrófico de desastres em cadeia, e apontam para o colapso das civilizações" (2019, p. 50), afirma. Uma saída possível seria fraternizar as incertezas, salvaguardando e regenerando as fraternidades dos oásis - reservas de resistência e fraternidade, insiste Morin (2019, p. 53), enfatizando que "devemos tomar o partido de Eros, que alimenta o amor e a fraternidade e propicia a imensa poesia de comunhão com o melhor que existe na humanidade".

Morin finaliza o livro assegurando que, para resistir à crueldade do mundo, é necessário criar um caminho, mais do que perseguir um fim. Caminhar permite a aventura dos oásis e, neles, a possibilidade de produção de experiências de vanguardas para um futuro melhor. Sem dúvida, um grande desafio. Por fim, de minha parte, sugerir a todos e todas a leitura desta grande obra.

\section{Referências}

MORIN, Edgar. Fraternidade. Para resistir à crueldade do mundo. Trad: Edgard de Assis Carvalho. São Paulo: Palas Athena, $2019.59 \mathrm{p}$.

O ZOOLÓGICO de Varsóvia. Direção: de Niki Karo. Estados Unidos da América: Netflix, 2017. (127 min.) 